\title{
Silva RM, Ramalho ERFM, Fernandes AFC. Challenges in the assistance to the health of the woman and emerging themes. Fortaleza: Edições UFC; 2012
}

Karla de Abreu Peixoto Moreira ${ }^{1}$

The Health of the Woman encompasses several themes in a very wide area of care in all the phases of life, whether in childhood, in adolescence, in the reproductive period or in climacteric. In each phase of life, there are peculiarities which deserve to be understood and, so, be directed to the actions of health. For such, the constant and permanent professional updating is necessary.

The book Challenges in the Assistance to the Health of the Woman and Emerging Themes, organized by Raimunda Magalhães da Silva, Escolástica Rejane Ferreira Moura Ramalho and Ana Fátima Carvalho Fernandes, has 330 pages divided in five parts: contributions for the promotion of pregnancy; contributions to the assistance of the pre-natal; promotion of health: what is possible in the assistance to delivery and puerperium; coping of mastectomy and emergent themes. The book provides 17 results of scientific researches in the area of the health of the woman, compiled by 74 authors, joining multi-professional and interdisciplinary knowledge which reveal results of studies that contribute to the widening of knowledge in this area.

The presentation of the work describes that its emergence occurred from the encounter among three groups or research turned to questions which involve the health of the woman of different Universities, portraying results of researches of the graduation and post-graduation. According to the organizers this collection of knowledge integrates theoretical and practical questions revealing the complexity and the challenges that the health professionals and the services of health care must face, surpassing the limits of the process of health care of the woman.

In part 1, contributions for the promotion of pregnancy, the authors describe analysis on the sexual and reproductive aspects which involve the period of adolescence. Under the focus of family planning the use of hormonal anti-contraception and the male preservative are the methods of anti-contraceptive choice of the adolescents, accordingly with the partner, considered by them the most available and publicized method.

It is worth highlighting that the adolescents researched reported dissatisfaction regarding the net of services, difficulty of access to the anti-contraceptive method by the waiting for the assistance or distance between the health care and their homes. Regarding the reason of pregnancy in this period, the adolescents attributed carelessness or by their personal desire and the desire of the couple to get pregnant. Despite of that, feelings of sadness, need of happiness attacked these adolescents, who still projected expectation of future, such as keep on studying and working. The family experiences this pregnancy positively with support, happiness and acceptance, and this support is indispensable to these adolescents. This familiar support can decrease the number of abortions provoked by undesired and unplanned pregnancy and, with this, avoid the maternal death. A theme still discoursed by the authors, the maternal mortality in Fortaleza, Brazil, in the period of 2004 to 2010 , still has as main cause the direct obstetrics, and the hypertensive syndromes are the majority.

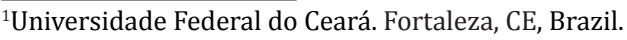


In this analysis, it is observed that the women are still dying due to avoidable and preventable causes. The acting of Committees of Maternal Mortality, the real notifications and the structuring of the net of assistance to the woman in the gravidic-puerperal period can collaborate for an improvement in these indicators.

Contributing to the assistance to pre-natal, the authors discourse on the pre-natal assistance in the Family Strategy Health. The self-evaluation of nurses and doctors, especially in the precarious conditions of work, with few human resources and materials; the perceptions of the pregnant women on pregnancy and on the pre-natal nursing appointments are based in the need of directed orientations on pregnancy, delivery and post-partum; the establishment of link in the pre-natal between the pregnant woman and the health professional is indispensable, especially in the cases of high risk and for an early diagnosis of diseases, such as the hypertensive syndromes. The importance of education in health is emphasized as a continuous and effective practice in pre-natal and as strategy of health promotion of the pregnant women.

Afterwards, in the third section, comes the promotion of health as follows: what is possible in the assistance to delivery and puerperium, the authors emphasize the need of a favorable environment to the delivery as a strategy of promotion of health, such ambience was already established through the Technical Standard of Resolution of the Board of Directors no. 36 of the National Health Surveillance Agency, which established the technical regulation for the work of the services of obstetric and neo-natal care. The adequate ambiance regarding the singularities of the parturient and her instinctive freedom provides subsidies for a more positive experience in the process of delivery. Besides the respectful and ideal physical environment, verbal and body communication of the parturient and of the health professional must be based on respect and care, zeal for her body and autonomy with stimulus to an active participation throughout the process of delivery. The assistance in health in the puerperal period, under the perspective of the Family Health Strategies, is turned to physical and psychological alterations inherent to the need of the puerpera and her newborn, such as the promotion of exclusive breastfeeding, family planning and the prevention of the cervical cancer.

In part 4, coping of mastectomy, the authors focus on a theme which presents many myths and conflicts for the woman who had mastectomy and her family. Classifying her condition of health consists in understanding in which way this woman copes with the conditions of health-disease, based on the individual, social and biological perception and experiences. The groups of support are positive strategies to improve the emotional condition of the women who had mastectomy, and so, promote an emotional balance of self-motivation and self-care.

The book, still keeps a chapter to deal with emergent things, such as the sexuality of the blind women, focusing on breastfeeding; decrease of the bone mass in women: importance of the earl diagnosis and the healthy aging; pre-menstrual and dysphoric syndrome; citizenship and right to the health of women assisted in the Family Health Strategy as well as the violence against women in the Brazilian northeast.

It is a current and relevant work, interesting for all of those who choose to follow the path of the health of the woman, in its several areas of acting, whether in management, in assistance, in teaching or in the research. In this sense, the multidisciplinary character of the book transforms it in a tool which promotes a stimulus to the reflection on the practice in health of the woman in its interfaces. It is a recommended reading for the health professionals, students of graduation and post-graduation.

\section{Collaborations}

Moreira KAP contributed for the conception, writing and final approval of the text. 